\title{
PROSES EKSTRAKSI SENG OKSIDA DARI SENG DROSS MENGGUNAKAN METODE HIDROMETALURGI SISTEM TERBUKA
}

\author{
(EXTRACTION PROCESS OF ZINC OXIDE FROM ZINC DROSS USING \\ HIDROMETALURGI METHODE OPEN SYSTEM)
}

\author{
Siti Agustina \\ Balai Besar Kimia dan Kemasan, Kementrian Perindustrian \\ Jl. Balai Kimia no. 1 Pekayon, Pasar Rebo Jakarta Timur \\ E-mail : tinaratujaya@yahoo,com
}

Revised: 13 Juni 2016; receved: 1 Juli 2016; accepted: 21 September 2016

\begin{abstract}
ABSTRAK
Seng oksida merupakan jenis bahan kimia yang banyak digunakan oleh masyarakat, diantaranya adalah untuk industri kosmetik, industri kesehatan, industri karet dan industri pertanian. Pada saat ini dalam memenuhi kebutuhan seng oksida di dalam negeri sebagian impor dari negara lain. Untuk substitusi impor akan seng oksida maka dicari potensi bahan baku yang dapat digunakan untuk pembuatan seng oksida, diantaranya adalah seng dross yang merupakan hasil samping dari industri galvanis sistem hot-dip. Penelitian ini bertujuan untuk mendapatkan kondisi proses ekstraksi seng dross dengan asam asetat glasial, sehingga menghasilkan seng oksida. Pada proses ekstraksi menggunakan metode hidrometalurgi sistem terbuka, variabel yang divariasi adalah waktu proses ( 30 menit, 60 menit, 90 menit dan 120 menit), suhu proses $\left(150{ }^{\circ} \mathrm{C}, 170{ }^{\circ} \mathrm{C}\right.$ dan $190{ }^{\circ} \mathrm{C}$ ), dan konsentrasi asam asetat glasial ( $20 \%, 40 \%$ dan $60 \%$ ). Hasil penelitian menunjukkan bahwa kondisi proses yang terbaik adalah pada waktu 90 menit, suhu $150{ }^{\circ} \mathrm{C}$, dan konsentrasi asam asetat glasial $60 \%$, didapatkan rendemen sebesar $62,45 \%$ dan kadar seng dalam seng oksida adalah sebesar 70,23 \%. Berdasarkan analisis $X$-ray diffraction $(X R D)$ kristal seng oksida yang terbentuk sama dengan seng oksida standar. Seng dross berpotensi sebagai bahan baku untuk pembuatan seng oksida,sehingga dapat digunakan sebagai bahan substitusi impor.
\end{abstract}

Kata kunci: Seng dross, Ekstraksi, Seng oksida, Seng

\begin{abstract}
Zinc oxide is one of the chemical that widely used in public, such as for cosmetic industry, health industry, rubber industry and agricultural industry. For now, to fulfill the needs of zinc oxide in Indonesia we still have to import it from other countries. To substitute the import of zinc oxide, we need to find potential material that can be used to make zinc oxide, one of it is zinc dross which is the byproduct from hot-dip galvanizing industry. The purpose of this research is to get the condition of zinc dross extraction process with glacial acetic acid, so it will form zinc oxide. The extraction process will need hydrometallurgy method with time process variable (30 minutes, 60 minutes, 90 minutes and 120 minutes), temperature process $\left(150^{\circ} \mathrm{C}, 170^{\circ} \mathrm{C}\right.$ dan $190^{\circ} \mathrm{C}$ ) and glacial acetic acid concentration $(20 \%, 40 \%$, and $60 \%)$. The result for the research of extraction process of zinc oxide by using zinc dross shows that the best condition is 90 minutes for the time, $150^{\circ} \mathrm{C}$ for the temperature and $60 \%$ for the concentration of glacial acetic acid, it's also resulted in $62,5 \%$ of it and the level of concentration of zinc in it is by $70,23 \%$. Based on XRD analysis, zinc oxide crystal that was form is equal to the standard zinc oxide. So, Zinc dross is a potential material to make zinc oxide and also it can be used as import substitution material.
\end{abstract}

Key words: Zinc dross, Extraction, Zinc oxide, Zinc

\section{PENDAHULUAN}

Seng oksida $(\mathrm{ZnO})$ banyak digunakan oleh masyarakat, yaitu sebagai bahan tabir surya pada industri kosmetik, bahan obat-obatan pada industri kesehatan, bahan vulkanisir pada industri karet, sebagai penstabil pada industri cat dan bahan unsur hara pada industri pertanian. Berdasarkan banyaknya kegunaan seng oksida untuk memenuhi kebutuhan 
masyarakat tersebut, maka pada saat ini seng oksida masih impor, berdasarkan data dari Pusdatin Kementerian Perdagangan, pada tahun 2009 sebesar 8.605. 416 US \$ dan tahun 2013 meningkat sebesar 16.877.414 US \$. Menurut Moezzi (2012) seng oksida digunakan untuk industri karet, industri logam (galvanis secara kontinu, galvanis umum, proses pembuatan kuningan), dan untuk bahan kimia. Menurut Sugiyarto et al (2010), sumber seng di alam dapat berupa mineral, yang berikatan dengan senyawa lain, misalnya wutzik ( $\mathrm{ZnS})$, smithsonites $\left(\mathrm{ZnCO}_{3}\right)$, willenite $\left(\mathrm{Zn}_{2} \mathrm{SiO}_{4}\right)$, zincite $(\mathrm{ZnO})$, zinkosite $\left(\mathrm{ZnSO}_{4}\right)$, frakinite $\left(\mathrm{ZnFeSO}_{4}\right)$ dan hopeite $\left(\mathrm{Zn}_{3}\left(\mathrm{PO}_{4}\right)_{2} \quad 4 \mathrm{H}_{2} \mathrm{O}\right)$. Seng oksida dapat diperoleh dari pembakaran logam seng karbonat dengan persamaan sebagai berikut:

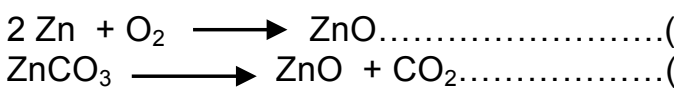

Seng oksida dapat diproduksi menggunakan berbagai jenis proses, yaitu : (1) oksidasi logam seng, (2) reduksi logam dengan sistem kontrol reoksidasi dan (3) proses pengendapan oksida logam dan logam karbonat. Selanjutnya dapat juga diproduksi dari limbah industri dengan menggunakan proses hidrometalurgi atau proses pirometalurgi. Pada proses hidrometalurgi menggunakan pelarut asam atau basa, sedangkan pada proses pirometalurgi menggunakan suhu tinggi (Rao 2006). Beberapa penelitian yang telah dilakukan untuk mendapatkan seng oksida dari limbah industri, yaitu sludge dari proses basic oxygen furnace menggunakan $\mathrm{NH}_{4} \mathrm{Cl}$ (Gargul et al. 2014), abu dari proses oxygen furnace menggunakan asam sulfat (Trung et al. 2014), limbah samsonit (calcium carbonat) dikalsinasi (Zhang et al. 2013), limbah zinc ferrite dengan asam klorida (Langova et al. 2009). Terdapat beberapa metode untuk pengambilan kembali seng dari limbah adalah metode ekstraksi dengan asam sulfat (Barakat. 1999), metode electrorefining dengan ammonium khlorida (Huajun et al. 2007), metode kombinasi pemanasan, ekstraksi dan pemisahan secara magnetik (Yan et al. 2014), metode ekstraksi asam asetat (Agustina et al. 2014).

Meningkatnya kebutuhan bahan yang berlapis logam seng, menyebabkan meningkatnya produksi industri pelapisan logam baik yang menggunakan sistem elektroplating maupun sistem hot dip galvanis. Hal ini meningkatkan juga hasil samping dari industri pelapisan logam tersebut. Pada setiap industri galvanis sistim hot-dip rata-rata menghasilkan seng dross sebanyak $10 \%$ sampai dengan 15\% dari jumlah seng yang digunakan pada proses produksi pelapisan logam (Rao 2006; Prasad 2008). Hasil samping dari industri sistem hot dip galvanis berupa seng yang terapung disebut seng dross. Seng dross mempunyai kandungan seng yang cukup tinggi, yaitu $90 \%$ sampai dengan $98 \%$ (Maaß et al. 2011). Pada saat ini seng dross diekspor ke negara lain, terutama ke negara China. Di dalam negeri sebagian seng dross dimanfaatkan untuk bahan pembuatan kuningan.

Berdasarkan kebutuhan seng oksida oleh masyarakat yang masih impor dan potensi tersedianya bahan baku seng di dalam negeri, maka dilakukan penelitian yang bertujuan untuk memanfaatkan seng dross dari hasil samping industri galvanis sistem hot dip untuk mendapatkan seng oksida dengan menggunakan proses ekstraksi seng dengan metoda hidrometalurgi sistem terbuka.

Pada penelitian ini menggunakan asam asetat sebagai bahan pelarut dikarenakan asam asetat tidak mengandung senyawa yang bersifat toksik. Senyawa didalamnya adalah hidrogen, karbon dan oksigen. Pada proses ekstraksi seng dengan asam asetat, akan terbentuk larutan seng asetat. Dengan adanya oksigen, maka akan terjadi proses oksidasi, sehingga akan menghasilkan seng oksida.

\section{BAHAN DAN METODE}

\section{Bahan}

Bahan yang digunakan adalah seng dross dari hasil samping industri galvanis di daerah Cikarang, asam asetat glasial (Merck), aquades, asam nitrat (Merck), larutan standar seng.

Alat yang digunakan adalah alat pengecil partikel (crusher), saringan, peralatan gelas, oven memmert, pemanas listrik Selecta multimatic $5 N$, magnetic stirrer Magsuda SM 60 $N$, stopwatch Seiko, neraca analitis Satorius BSA 2245-CW, pengaduk, termometer, Atomic Absorption Spectrofotometer (AAS) Shimatsu, $X$-Ray Diffraction (XRD) GPC type Emma.

\section{Metode}

Metode penelitian dilakukan dalam 3 tahap, yaitu tahap pengecilan seng dross, tahap proses ekstraksi, dan tahap analisis hasil.

Pada tahap pengecilan ukuran, seng dross di crusher, diayak sampai berukuran 150 mesh, selanjutnya dianalisis konsentrasinya dengan menggunakan Atomic Absorption Spectrofotometer (AAS). Seng dross sebanyak 20 gram diekstraksi dengan larutan asam asetat glasial melalui hidrometalurgi sistem terbuka. 
Pada proses ini digunakan beberapa variabel, diantaranya waktu ekstraksi, yaitu 30 menit, 60 menit, 90 menit, dan 120 menit; suhu ekstraksi $150{ }^{\circ} \mathrm{C}, 170{ }^{\circ} \mathrm{C}, 190{ }^{\circ} \mathrm{C}$ serta konsentrasi asam asetat glasial 20\%. Endapan yang terbentuk berupa seng oksida, dianalisis dengan menggunakan Atomic Absorption Spectrofotometer (AAS) untuk mengetahui konsentrasi seng yang terdapat di dalam seng oksida, selanjutnya dianalisis menggunakan $X$-ray Diffraction yang bertujuan untuk mengidentifikasi kristal seng oksida yang terbentuk.

\section{HASIL DAN PEMBAHASAN}

\section{Karakterisasi Seng Dross}

Seng dross merupakan hasil samping dari industri galvanis sistem hot-dip. Seng dross yang diperoleh dari industri berupa logam hasil cetakan dengan ukuran panjang $20 \mathrm{~cm}$ dan diameter $10 \mathrm{~cm}$, setelah dilakukan pengecilan partikel, maka akan didapatkan seng dross dalam bentuk bubuk ukuran 150 mesh, selanjutnya dianalisis dengan menggunakan Atomic Absorption Spectrofotometer (AAS) untuk mengetahui kandungan seng yang terdapat didalam seng dross. Hasil analisis menunjukkan kandungan seng dross terdiri dari seng sebesar 96,57 \%, Pb $=1,98 \%$ dan besi sebesar 2,04 \%. Dari hasil analisis menunjukkan bahwa seng dross potensi untuk dilakukan proses ekstraksi seng, karena memiliki kandungan seng yang tinggi. Pada proses ekstraksi dengan pelarut asam, kandungan seng pada bahan baku sangat penting. Ini berguna, dalam menentukan jenis pelarut yang akan digunakan, kalau kandungan seng nya tinggi (90\% lebih) dapat menggunakan pelarut asam lemah, tetapi kalau kandungan seng nya tidak terlalu tinggi, maka disarankan untuk menggunakan pelarut asam kuat. (Agustina et al. 2015).

\section{Proses Ekstraksi Seng Dross Sebagai Seng Oksida}

Proses ekstraksi seng dross dengan asam asetat glasial menggunakan pemanasan sistem terbuka akan menghasilkan garam seng berupa seng oksida, dapat dilihat pada persamaan reaksi berikut ini :

$\mathrm{Zn}+2 \mathrm{CH}_{3} \mathrm{COOH} \rightarrow \mathrm{Zn}\left(\mathrm{CH}_{3} \mathrm{COO}\right)_{2}+\mathrm{H}_{2}(3)$ $\mathrm{Zn}\left(\mathrm{CH}_{3} \mathrm{COO}\right)_{2}+1 / 2 \mathrm{O}_{2} \rightarrow \mathrm{ZnO}+2 \mathrm{CH}_{3} \mathrm{COO}$ (4)

Pada penelitian ini dilakukan proses ekstraksi seng dross dengan asam asetat glasial dengan menggunakan variabel waktu ekstraksi yaitu : 30 menit, 60 menit, 90 menit dan 120 menit. Menggunakan proses hidrometalurgi sistem terbuka, bertujuan untuk dapat melakukan kontak dengan oksigen secara kontinyu, sehingga akan mendapatkan proses oksidasi secara maksimal. Suhu yang digunakan adalah $150{ }^{\circ} \mathrm{C}$.

Hasil penelitian dapat dilihat pada Gambar 1, menunjukkan bahwa pada konsentrasi asam asetat glasial $60 \%$ menghasilkan kadar seng yang tertinggi pada seng oksida. Pada waktu ekstraksi 30 menit kadar seng yang dihasilkan adalah sebesar $12,33 \%$, pada 60 menit sebesar $13,31 \%$, pada 90 menit sebesar $33,74 \%$ dan pada 120 menit adalah $34,97 \%$. Proses ekstraksi seng dross menunjukkan bahwa waktu yang terbaik adalah 90 menit. Ini menunjukkan bahwa dengan pertambahan konsentrasi seng, akan menghasilkan kadar seng makin tinggi, tetapi dengan pertambahan waktu kadar seng yang dihasilkan tidak berbeda secara signifikan. Menurut Taner (2016) faktor yang mempengaruhi proses hidrometalurgi (leaching) seng dari karbon baterai dengan asam asetat adalah konsentrasi asam asetat, suhu, ukuran partikel dan kecepatan pengaduk. Hasil penelitian menunjukkan makin tinggi konsentrasi asam asetat, akan menghasilkan makin tinggi kadar seng dan makin lama waktu akan menghasilkan kadar seng makin tinggi, dimana hasil terbaik adalah suhu $60{ }^{\circ} \mathrm{C}$, waktu 240 menit, kecepatan pengadukan 600 rpm, konsentrasi asam asetat $4 \mathrm{M}$ dan ukuran partikel $53 \mu \mathrm{m}$. Hasil yang sama didapat dari hasil penelitian Deng (2015) untuk proses hidrometalugri (leaching) pada seng didalam tungsten dengan pelarut asam trikloroasetat, hasil yang terbaik adalah suhu $60^{\circ} \mathrm{C}$, waktu 20 menit, ukuran partikel $53 \mu \mathrm{m}$, kecepatan pengadukan 1000 rpm dan konsentrasi asam $1,25 \mathrm{ml} / \mathrm{l}$. Kedua proses hidrometalurgi diatas merupakan proses secara tertutup.

Pada penelitian ini asam asetat merupakan asam elektrolit lemah yang mempunyai ikatan ion dan ikatan kovalen (Day et al.. 2002). Pada proses ekstraksi seng, asam asetat berfungsi sebagai pelarut untuk berikatan ion dengan seng sehingga terbentuk ikatan ion antara seng dan asam asetat, yaitu berupa larutan seng asetat, selanjutnya seng asetat mengalami proses oksidasi, sehingga ikatan ion tersebut putus dan seng berikatan dengan oksigen menjadi seng oksida. Seng oksida yang dihasilkan lebih aman untuk dipergunakan, Terutama untuk kosmetik dan obat-obatan, selain itu bersifat ramah lingkungan. 


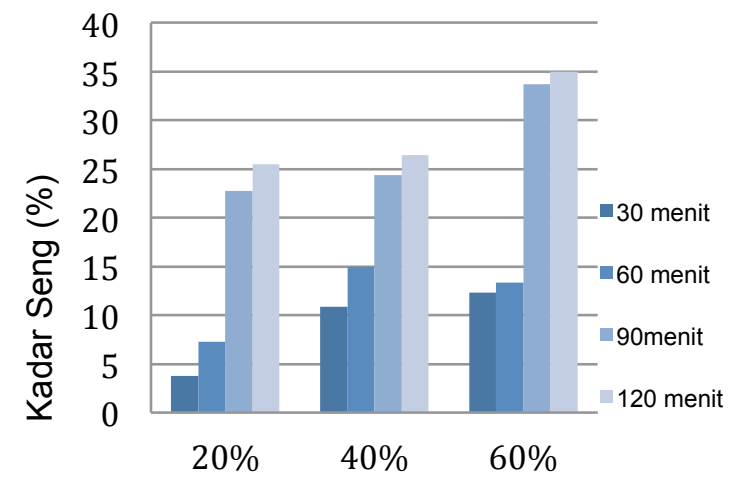

Konsentrasi asam asetat glasial (\%)

Gambar 1. Grafik hubungan kadar seng (\%) dengan konsentrasi asam asetat (\%) dan waktu ekstraksi (menit) pada ekstraksi dengan suhu $150{ }^{\circ} \mathrm{C}$

Setelah diketahui waktu yang terbaik pada proses ekstraksi seng dari seng dross sebagai seng oksida, maka dilanjutkan dengan proses ekstraksi seng menggunakan variabel suhu ektraksi dan konsentrasi asam asetat glasial. Suhu yang digunakan adalah $150{ }^{\circ} \mathrm{C}$, $170{ }^{\circ} \mathrm{C}$, dan $190{ }^{\circ} \mathrm{C}$. Konsentrasi asam asetat glasial adalah $20 \%, 40 \%$ dan $60 \%$. Pada proses ekstraksi seng dross dengan asam asetat dengan metode hidrometalurgi sistem terbuka akan menghasilkan seng oksida dengan kadar seng sebesar $70,23 \%$, pada kondisi proses adalah waktu ekstraksi 90 menit, suhu ekstraksi $150{ }^{\circ} \mathrm{C}$ dan konsentrasi asam asetat sebesar $60 \%$. Lebih jelas dapat dilihat pada Gambar 2.

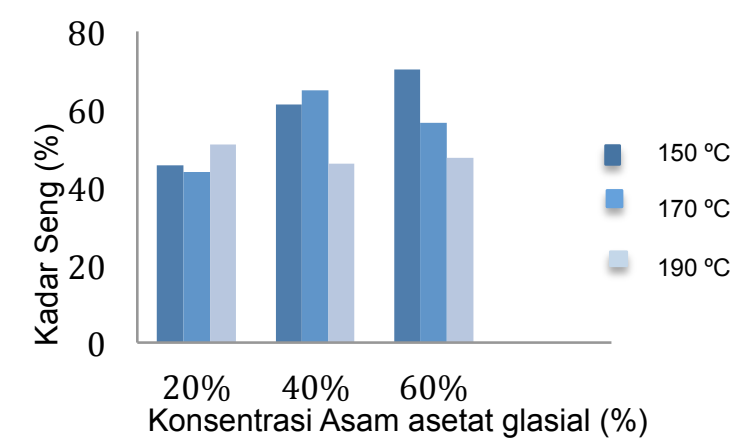

Gambar 2. Grafik hubungan kadar seng (\%) dengan konsentrasi asam asetat (\%) dan suhu ekstraksi $\left({ }^{\circ} \mathrm{C}\right)$ pada waktu 90 menit.

Pada konsentrasi asam asetat $20 \%$, menunjukkan makin tinggi suhu akan menghasilkan kadar seng makin tinggi. Pada konsentrasi asam asetat $40 \%$ menunjukkan bahwa pada suhu $150{ }^{\circ} \mathrm{C}$ dan suhu $170{ }^{\circ} \mathrm{C}$ kadar meningkat, tetapi pada suhu $190^{\circ} \mathrm{C}$ terjadi penurunan kadar seng. Hal ini disebabkan adanya ketidakseimbangan pada volume larutan, sehingga kadar seng yang terserap lebih sedikit. Pada proses hidrometalurgi sistem terbuka terjadi proses penguapan, sehingga volume larutan mengalami pengurangan. Pada konsentrasi asam asetat $60 \%$, menunjukkan bahwa makin tinggi suhu maka kadar seng semakin rendah. Ini menunjukkan bahwa pada suhu $150^{\circ} \mathrm{C}$ menghasilkan kadar seng tertinggi, karena makin tinggi suhu akan makin banyak volume larutan berkurang, sehingga akan terjadi ketidakseimbangan proses pelarutan seng. Kalau pada metode hidrometalurgi sistem tertutup makin tinggi suhu akan menghasilkan kadar seng makin tinggi ( Taner et al. 2016 dan Deng et al. 2015), sedangkan pada metode hidrometalurgi sistem terbuka, makin tinggi suhu akan menghasilkan kadar seng makin rendah, karena volume berkurang pada waktu konstan.

Beberapa penelitian melakukan proses ekstraksi seng dari limbah dengan menggunakan pelarut asam dan basa diantaranya adalah Moezzi et al (2012) recovery seng dari limbah seng dross dan abu seng dapat dilakukan dengan metode hidrometalurgi menggunakan asam sulfat atau sodium ditiosianat atau sodium hidroksida atau dapat juga ammonium hidroksida, seperti reaksi dibawah ini :

$2 \mathrm{NaHSO}_{3}+\mathrm{Zn} \rightarrow \mathrm{Na}_{2} \mathrm{~S}_{2} \mathrm{O}_{4}+\mathrm{ZnO}+\mathrm{H}_{2} \mathrm{O} \ldots \ldots(5)$
$5 \mathrm{ZnSO}_{4} \cdot 7 \mathrm{H}_{2} \mathrm{O}+5 \mathrm{Na}_{2} \mathrm{CO}_{3} \rightarrow \mathrm{Zn}_{5}\left(\mathrm{CO}_{3}\right)_{2}(\mathrm{OH})_{6}+$

$5 \mathrm{ZnS}_{2} \mathrm{SO}_{4}+3 \mathrm{CO}_{2}+32 \mathrm{H}_{2} \mathrm{O} \ldots \ldots \ldots \ldots \ldots \ldots \ldots \ldots \ldots \ldots \ldots \ldots \ldots \ldots$

$\mathrm{Zn}_{5}\left(\mathrm{CO}_{3}\right)_{2}(\mathrm{OH})_{6}+$ Heat $\rightleftharpoons 5 \mathrm{ZnO}+2 \mathrm{CO}_{2}+3 \mathrm{H}_{2} \mathrm{O}(7)$

$\mathrm{ZnSO}_{4}+2 \mathrm{NaOH} \rightarrow \mathrm{ZnO}_{(\mathrm{s})}+\mathrm{Na}_{2} \mathrm{SO}_{4}+\mathrm{H}_{2} \mathrm{O} \ldots$ (8)

Pada recovery seng dari limbah industri logam dengan menggunakan asam klorida dapat menghasilkan seng klorida yang mempunyai kadar seng sebesar 97\%, kondisi proses yang digunakan adalah waktu selama 48 menit, suhu sebesar $65^{\circ} \mathrm{C}$ dan konsentrasi asam klorida sebesar $3 \mathrm{M}$ (Bese et al. 2010).

\section{Struktur Kristal Seng Oksida}

Kristal adalah suatu padatan dimana molekul atom atau ion penyusunnya tersusun dalam suatu pola tertentu. Pertumbuhan kristal dipengaruhi oleh kecepatan kristalisasi, derajat supersaturasi, suhu, $\mathrm{pH}$, kandungan zat lain (impurities), jenis pelarut dan pengadukan (Fachry et al. 2008). Seng oksida yang dihasilkan dari proses ekstraksi antara seng dross dan larutan asam asetat glasial, kemudian dianalisis dengan menggunakan $X$-ray Diffraction (XRD) yang bertujuan untuk mengidentifikasi kristal seng oksida yang 
terbentuk. Hasil analisis $X$-Ray Diffraction $(X R D)$ seng oksida dapat dilihat pada Gambar 3.

Berdasarkan analisis $X R D$ menunjukkan bahwa seng oksida yang dihasilkan dari proses ekstraksi seng dross dan asam asetat glasial merupakan seng oksida yang sesuai dengan standar seng oksida, karena mempunyai derajat 2 theta sama dengan seng oksida standar, yaitu pada hkl $31^{\circ}=100,34^{\circ}=002,36^{\circ}=101,47^{\circ}=$ $102,56^{\circ}=110,63^{\circ}=103,66^{\circ}=200,68^{\circ}=112$, $69^{\circ}=201,72^{\circ}=004,77^{\circ}=202$. Struktur logam yang terdiri dari atom-atom logam, menjadi satu kesatuan membentuk satuan sel sistem kristal. Terdiri dari (a) kubus primitif, (b) kubus pusat badan bcc, (c) kubus pusat muka fcc dan heksagonal hcp. Pada umumnya kristal seng mempunyai struktur logam hcp atau heksagonal. (Sugiyarto 2010).

\section{Rendemen Seng Oksida}

Proses ekstraksi seng dross dengan asam asetat dengan metode hidrometalurgi sistem terbuka akan menghasilkan seng oksida. Jumlah kuantitas seng oksida yang dihasilkan dibandingkan dengan seng dross yang digunakan, dinyatakan sebagai rendemen seng oksida.

Pada penelitian ini menghasilkan seng oksida dengan rendemen yang tertinggi dihasilkan dari kondisi proses waktu ekstraksi 90 menit, suhu ekstraksi $150^{\circ} \mathrm{C}$ dan konsentrasi asam asetat $60 \%$, yaitu sebesar $62,45 \%$ seperti terlihat pada Gambar 4. Hasil ini menunjukkan bahwa seng dross dengan proses ekstraksi seng metode hidrometalurgi sistem terbuka dengan pelarut asam asetat dapat menghasilkan seng oksida.

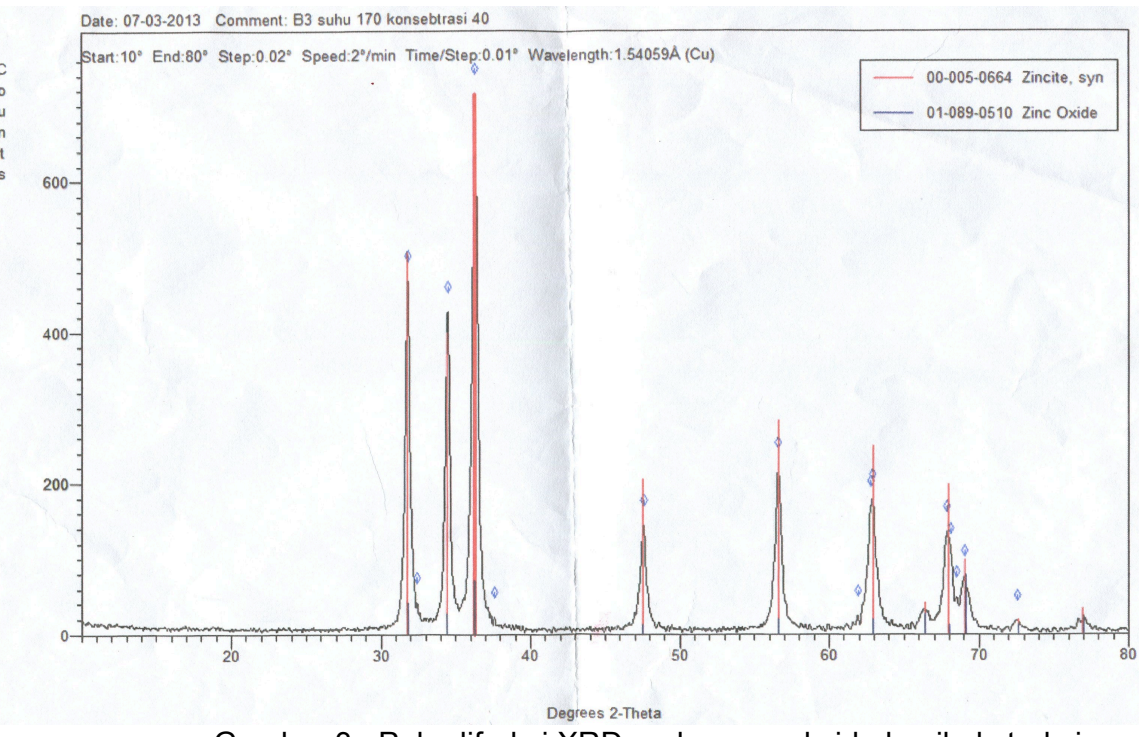

Gambar 3. Pola difraksi XRD pada seng oksida hasil ekstraksi

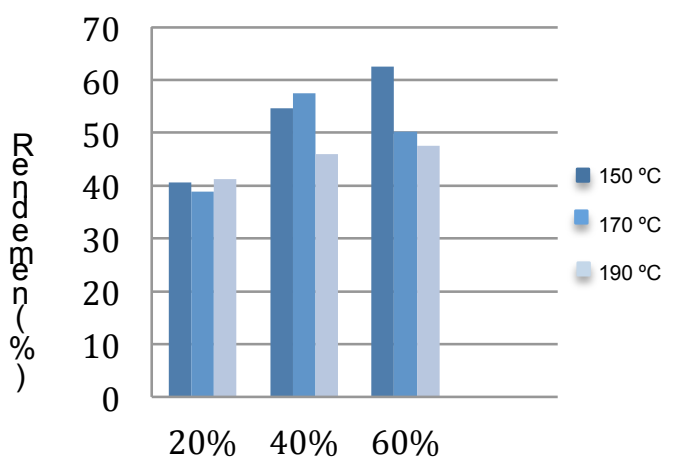

Konsentrasi Asam asetat glasial (\%)

Gambar 4. Grafik hubungan rendemen seng (\%) dengan konsentrasi asam asetat (\%) dan suhu ekstraksi $\left({ }^{\circ} \mathrm{C}\right)$ pada waktu 90 menit.

\section{KESIMPULAN}

Seng dross dari hasil samping industri galvanis sistem hot-dip berpotensi sebagai bahan baku untuk proses pembuatan seng oksida. Pada proses ekstraksi seng dari seng dross menjadi seng oksida, kondisi proses yang baik adalah waktu ekstraksi 90 menit, konsentrasi asam asetat glasial sebesar $60 \%$, suhu proses sebesar $150^{\circ} \mathrm{C}$, dan ukuran partikel seng dross 150 mesh. Proses ekstraksi tersebut menghasilkan seng oksida dengan rendemen $62,45 \%$ dan kadar seng dalam seng oksida sebesar $70,23 \%$. 


\section{DAFTAR PUSTAKA}

Agustina, S., S.N. Indrasti, Suprihatin, dan N.T. Rochman. 2014. Pemanfaatan limbah industri galvanis sebagai seng asetat. Jurnal Kimia dan Kemasan. 36(1): 149152

Agustina S. 2015. Rekayasa proses sintesa nano seng oksida dari hasil samping industri galvanis sebagai bionanokomposit kemasan antimikroba. Disertasi. Sekolah pasca sarjana. IPB. Bogor.

Barakat, M. A. 1999. Recovery of metal values from zinc soder dross. Waste management 19: 503 -507.

Bese, A.V., N. Borulu, M. Copur, and S. Colak. 2010. Optimization of dissolution of metals from waelz sintering waste (WSW) hydrochloric acid solutions. Chemical engineering journal. 162(2): 718-722

Day R. A. J. R, A. L. Underwood 2002. Analisis kimia kuantitatif. Erlangga. Jakarta.

Deng .J, Q. Sun, P. Lin, G. Song, S. M. Wea, J. Y. Deng and D. Wu. 2015. Dissolution kinetic of zinc oxide ore with organic acid. International journal of metallurgical \& materials engineering. 1(1): 1-7.

Fachry A. R., T. Juliyadi, N. P. Endah, and I. Yani. 2008. Pengaruh waktu kristalisasi dengan proses pendinginan terhadap pertumbuhan kristal ammonium sulfat dari larutannya. Jurnal Teknik Kimia. 2:15-16

Huajun Z, G. Zhonghaj, and Z. Jinhuan. 2007. Study on the dissolution process of zinc anoe in ammoniacal ammonium chloride system. Hydrometallurgy. $89(3-4)$ : 369-373

Gargul K. and B. Boryzko 2014. Removal of zinc from dusts and sludges from basic oxygen furnaces in the process of ammoniacal leaching. Archives of civil and mechanical engineering, University 15(1): 179-187
Langova, S., J. Lesko, and D. Matysek. 2009. Selective leaching of zinc ferrite with hydrochloric acid. Hydrometallurgy. 25(3-4): 179-182

Maaß, P., P. Peissler, and C. Ahner. 2011. Hand book of hot dip galvanization: 6-25, Wiley

Moezzi, A., A. M. Donagh, and M. B. Contie. 2012. Zinch oxide particles : synthesis, properties and applications. Chemical engineering journal. 185-186: 1-22

Prasad S. 2008. Zinc dross problem in galvanizing and its use to produce electrolytic zinc powder. Prospect problem and potential of coated steels. ISCS.70-76

Rao S. R. 2006. Resources recovery and recycling from metallurgical wastes, wastemanagement series 7 . Departement of mining, metals and material engineering. Mc Grill university. Montreal Quebec. Canada. Elsevier.

Sugiyarto, K. H., and R. D. Suyanti. 2010. Kimia anorganik logam. Graha IImu. Yogjakarta.

Taner, H. A., T. Agacayak, and A. Atas. 2016. Leaching of zinc and manganese from spent zinc- carbon batteries in acetic acid solution. Selcuk university journal of engineering, science \& technology. 4(3): 231- 236.

Trung, Z. H., F. Rukurugya, Z. Takaova, D. Orac, M. Laubertova, A. Miskufova, and T. Haulik. 2014. Acidic leaching both of zinc and iron from basic oxygen furnace sludge. Journal of hazardous materials. 192(3): 1100-1107

Yan H, L.Y. Clai, B. Peng, M. Li, M. Peng, D. Hou. 2014. A novel method recovery zinc and iron from leaching residue. Mineral engineering. 55: 103-110

Zhang Y, J. Deng, J. Cheng, R. Yu, and X. Xing. 2013. Leaching of zinc calcined smith sonite using sodium hydroxide. Hydrometallurgy.131-132 